\title{
Nutritional health attitudes and behaviors and their associations with the risk of overweight/obesity among child care providers in Michigan Migrant and Seasonal Head Start centers
}

\author{
Won O. Song ${ }^{1 *}$, SuJin Song ${ }^{1}$, Violeta Nieves ${ }^{1}$, Andie Gonzalez ${ }^{1}$ and Elahé T. Crockett ${ }^{2}$
}

\begin{abstract}
Background: Children enrolled in Migrant and Seasonal Head Start (MSHS) programs are at high risks of health problems. Although non-family child care providers play important roles on children's health status as role models, educators, program deliverers, and information mediators, little is known about their nutritional health attitudes and behaviors, and weight status. Therefore, we investigated nutritional health attitudes and behaviors and their associations with overweight/obesity among child care providers in Michigan MSHS centers.
\end{abstract}

Methods: A total of 307 child care providers aged $\geq 18$ years working in 17 Michigan MSHS centers were included in this cross-sectional study conducted in 2013. An online survey questionnaire was used to collect data on nutritional health attitudes and behaviors of child care providers. Weight status was categorized into normal weight $(18.5 \leq \mathrm{BMI}$ $\left.<25 \mathrm{~kg} / \mathrm{m}^{2}\right)$, overweight $\left(25 \leq \mathrm{BMl}<30 \mathrm{~kg} / \mathrm{m}^{2}\right)$, and obese $\left(\mathrm{BMl} \geq 30 \mathrm{~kg} / \mathrm{m}^{2}\right)$ based on child care providers' self-reported height and weight. Factor analysis was performed to investigate patterns of nutritional health attitudes and behaviors. Multivariate logistic regression was conducted to estimate the odds ratios (ORs) and $95 \%$ confidence intervals (Cls) of overweight/obesity across tertiles of pattern scores taking the lowest tertile group as the reference group after adjustment for potential confounding variables.

Results: Three patterns of nutritional health attitudes and behaviors were identified: pattern 1) "weight loss practices with weight dissatisfaction", pattern 2) "healthy eating behaviors", and pattern 3) "better knowledge of nutrition and health". The pattern 1 scores were positively associated with overweight/obesity (Tertile 2 vs. Tertile 1: OR $=5.81$, $95 \% \mathrm{Cl}=2.81-12.05$; Tertile 3 vs. Tertile 1: $\mathrm{OR}=14.89,95 \% \mathrm{Cl}=6.18-35.92)$. Within the pattern 2, the OR for overweight/obesity in individuals with the highest scores was $0.37(95 \% \mathrm{Cl}=0.19-0.75)$ compared with those with the lowest scores. However, the pattern 3 was not associated with the risk of overweight/obesity.

Conclusions: Our findings support that nutrition education or health interventions targeting MSHS child care providers are urgently necessary. These efforts might be an efficient and effective approach for improving the nutritional health status of young children enrolled in MSHS programs.

Keywords: Nutritional health behavior, Overweight, Obesity, Migrant and Seasonal Head Start, Child care provider, Childhood obesity

\footnotetext{
* Correspondence: song@anr.msu.edu

1 Department of Food Science and Human Nutrition, Michigan State

University, East Lansing, Ml 48824, USA

Full list of author information is available at the end of the article
} 


\section{Background}

A Migrant and Seasonal Head Start (MSHS) provides comprehensive early childhood education services for children ages zero to five years from Migrant and Seasonal Farm Worker (MSFW) families to promote school readiness and to help them grow physically, mentally, emotionally, and socially [1]. It was established in 1969 to respond to the needs of MSFWs [1], who are individuals employed in agricultural works on a seasonal basis with or without moving from their permanent residence [2]. The MSHS program differs from a regular Head Start program in that the participants being MSFWs' children, longer operation hours and remote rural locations, and programs staffed dominantly with Spanish speaking members $[1,3]$. The MSHS programs also offer health and nutrition related services, including nutritious meals and nutrition education to improve the overall health status of children [1]. In 2013, the MSHS program served 31,907 MSFWs' children nationwide [1].

Since MSFWs' children spend long hours with child care providers in MSHS centers, child care providers in MSHS centers working with children play an important role in the nutritional health status of MSFWs' children. Non-family child care providers are known to have the significant impact on the prevention of childhood obesity through role modeling of nutritional health behaviors and body image, teaching and practicing healthful dietary habits, implementing nutrition and health programs, and mediating information related to nutrition and health for families, parents, and children [4, 5].

However, only a few studies have examined non-family child care provider's nutritional health behaviors and their associations with child's health outcomes [6-8]. Regular Head Start teachers in Texas showed unhealthy dietary habits, such as low consumption of fruits and vegetables, high consumption of fried foods and soda and thus had a high prevalence of overweight/obesity [8]. Child care providers in licensed child care programs in rural Southern Illinois had low nutrition knowledge and inappropriate child feeding behaviors at mealtime [7]. In addition, feeding behaviors of child care providers working in Head Start in Texas were associated with children's food consumption [6]. Little is known about the nutritional health attitudes and behaviors among child care providers in MSHS programs.

Child care providers in MSHS centers are of particular importance due to their unique needs and great impact on the nutritional health status in MSFWs' children, who are vulnerable to overweight/obesity [9-11]. In addition, identifying patterns of nutritional health attitudes and behaviors can capture the complex nature of nutritional health attitudes and behaviors based on their inter-correlations and provide a comprehensive approach to explore their relationships with health outcomes. Understanding nutritional health attitudes and behaviors and their associations with weight status among MSHS child care providers is the first step to develop intervention strategies to improve their health status and ability to deliver MSHS programs to young children. Ultimately, these efforts might lead to improve the nutritional health status among MSFWs' children through a positive role modeling and successful implementation of MSHS programs by child care providers. Therefore, the aim of this study was to investigate patterns of nutritional health attitudes and behaviors and examine their associations with overweight/ obesity among child care providers in Michigan MSHS centers.

\section{Methods}

\section{Study design and participants}

Michigan Telamon Corporation provides MSHS services to young children aged zero to five years from MSFW families in 18 centers throughout the state. To be eligible for MSHS services, primary source of family income must come from qualifying agricultural activities and qualify based on income guidelines. Michigan MSHS centers offers partial or full day services with season varies from 10-26 weeks but primarily runs from June through October [12].

In the summer of 2013, Michigan Telamon Corporation collaborated with a research team in the Department of Food Science and Human Nutrition at Michigan State University to conduct a nutritional needs assessment for the overall goal of improving its MSHS programs and addressing the nutritional health risks that impact Michigan MSFW's children. This needs assessment was necessary in order to learn about the current nutritional health status of Michigan MSFW's children and how this is influenced by external factors, including sociodemographic characteristics, weight status, weight related perception and behaviors, nutritional health attitudes and behaviors, nutrition knowledge, and food availability and security of their parents and child care providers in MSHS centers. Our previous work examined the parental risk factors of childhood overweight/obesity in this population [11].

To answer the questions arisen from this study, data collected from child care providers who worked in 17 Michigan MSHS centers were used. The child care providers were defined as all employees worked in MSHS centers, including teachers and other staff who were aged 18 years or older. Study participants were recruited through an email in English and Spanish. The email indicated the instruction about the needs assessment and was disseminated to directors of all registered Michigan MSHS centers which had about 407 available child care providers. A total of 311 child care providers participated in this study (response rate: $76.4 \%$ ). Among them, two participants who had incomplete data on food availability and food security status and two participants who were underweight were 
excluded. Underweight is associated with other distorted eating behaviors related to anorexia and weight perceptions $[13,14]$, so we did not include them in the reference group of normal weight to avoid any potential problem with data interpretation occurring from inclusion of underweight participants. In addition, a very small number of participants were in the underweight category. Therefore, 307 child care providers were included in the final data analysis. We provided financial supports for a catered lunch to the participating centers as compensation. Our research team provided this compensation to the participating centers after the data collection was completed to avoid any potential bias in the answers from child care providers given in this study. However, each participant did not receive any incentives of participating in this study. The formal approval to conduct this needs assessment was obtained by the Institutional $\mathrm{Re}$ view Board of the Michigan Telamon Corporation. Informed written consent was obtained from each child care provider for collecting data by the research team.

\section{Data collection}

To collect data in this study, an online survey questionnaire was developed by nutritional professionals of the research team using an advanced and user-friendly online survey software tool (SurveyGizmo, Boulder, CO, USA). The completed computerized survey data were submitted via-online directly into a secured database, with limited access to those coordinating this project. The survey questionnaire link was sent via-email to each center and then distributed by each MSHS director to their child care providers. Prior to the dissemination of survey questionnaire link, we held a meeting with center directors to enhance their familiarity to this study, including the purposes, procedures, and the survey questionnaires. Directors guided their child care providers how to complete the survey questionnaire at each center. This self-administered survey given to child care providers in Michigan MSHS centers was completed within two weeks after its dissemination.

The survey questionnaire was divided into 1) sociodemographic characteristics, 2) weight status, 3) perception of weight, 4) nutrition knowledge, 5) food availability, 6) food security status, and 7) nutritional health attitudes and behaviors. Questions on sociodemographic characteristics included gender, age, race/ethnicity, marital status, and education level. Height and weight of child care providers were measured using calibrated portable scales that were located in MSHS centers by child care providers and then self-administered to the questionnaire. Body mass index (BMI) was calculated as weight (in $\mathrm{kg}$ ) divided by height squared (in $\mathrm{m}^{2}$ ). Weight status was categorized into normal weight $\left(18.5 \leq \mathrm{BMI}<25 \mathrm{~kg} / \mathrm{m}^{2}\right)$, overweight $(25 \leq$ $\left.\mathrm{BMI}<30 \mathrm{~kg} / \mathrm{m}^{2}\right)$, and obese $\left(\mathrm{BMI} \geq 30 \mathrm{~kg} / \mathrm{m}^{2}\right)$ based on the definition of overweight/obesity from the Centers for
Disease Control and Prevention [15]. Perception of their weight was answered as underweight, normal weight, overweight, or obese. Nutrition knowledge was evaluated using nine questions which were adopted from a part of the Head Start on Healthy Living Teacher Health Behavior Survey questionnaire validated and used in the previous study for Head Start teachers in Texas [8]. Nine questions were 1) Do drinks, like Fruitopia or Sunny Delight, count as a fruit serving?, 2) Do only fresh fruits and vegetables count towards the recommended daily servings of fruit and vegetables?, 3) Is it okay for children to eat without worrying about fat because they need lots of extra calories to grow?, 4) Are soft drinks low in fat?, 5) Are dairy products a good source of calcium?, 6) Should vitamin and mineral supplements be taken in addition to a healthy diet?, 7) How many servings of fruits and vegetables should you eat per day?, 8) What percent of your daily calories should come from fat?, and 9) What has the most calories?. A score of one was assigned to questions answered correctly, and a zero to a wrong answer or do not know response. The sum of the nutrition knowledge scores was the total nutrition knowledge score.

Food availability was assessed based on six questions related to the cost, quality, and accessibility of food, which were adopted from a part of the questionnaire used in the previous study examining the family food environments [16]. Food security status of adults was evaluated based on the 2012 US household food security survey module and was divided into four categories according to raw score: 1) high food security (score $=0), 2$ ) marginal food security (score 1-2), 3) low food security (score 3-5), and 4) very low food security (score 6-10) [17]. Fifteen questions regarding nutritional health attitudes and behaviors were adopted from a part of the Teens Eating for Energy and Nutrition at School teaching staff survey $[18,19]$ and answered as five-scale from strongly disagree to strongly agree.

\section{Statistical analyses}

All statistical analyses were conducted using SAS version 9.3 (SAS Institute Inc., Cary, NC, USA). To identify specific patterns of nutritional health attitudes and behaviors among child care providers, Principal Component Analysis with varimax rotation (PROC FACTOR and VARIMAX options in SAS) was performed based on 15 questions related to nutritional health attitudes and behaviors. As an input for factor analysis, the five-scale answers from strongly disagree to strongly agree for these questions were converted into continuous values from 1 to 5 to derive patterns. The output of factor analysis included all the eigenvalues, the factor loading matrix for eigenvalues greater than one, and computed factor scores. Factor scores for each pattern were calculated as the weighted sum scores by multiplying the score of each 
question into its factor loading and then summing all of them and the score for each identified pattern was given to each individual. To determine which patterns to retain, the eigenvalue, the factor loading matrix, and interpretability were considered [20]. The derived patterns were interpreted and named according to nutritional health attitudes and behaviors based on the questions with higher factor loadings $(\geq|0.40|)$ in each identified pattern. Because of non-normal distribution of pattern scores, individuals were categorized into three groups by tertiles of scores for each pattern.

Sociodemographic characteristics, weight status, perception of weight, nutrition knowledge level, food availability, and food security status across the tertiles of pattern scores were presented as means and standard deviation (SD) for continuous variables and as percentages (\%) for categorical variables. These variables across the tertiles of pattern scores were compared using the general linear model for continuous variables and the chi-square test for categorical variables. Multivariate logistic regression was performed to estimate odds ratios (ORs), $95 \%$ confidence intervals (CIs), and $p$-values for the prevalence of overweight/ obesity across the tertiles of pattern scores, taking the lowest tertile group as the reference group after adjustment for gender (male or female), age $(<30 y, 30-49 y$, or $\geq 50 y$ ), race/ethnicity (White/Caucasian, Black/African American, Hispanic/Latino, or other), marital status (single, married, cohabitating, or separated/divorced/ widowed), and education level ( $\leq$ high school or $\geq$ Associate's degree/certificate or college) as potential confounding variables. All statistical tests were two-sided, and a $p$ value $<0.05$ represented statistical significance.

\section{Results}

\section{Characteristics of Michigan MSHS child care providers}

Characteristics of Michigan MSHS child care providers are presented in Table 1. Michigan MSHS child care providers included in this study had 37.6 mean age $(\mathrm{SD}=13.5)$. About $92.2 \%$ of them were women and majority was White/Caucasian (44.3\%) or Hispanic/Latino (52.5\%). Child care providers who had associate's degree/ certificate or college degree were $45.6 \%$. The specific position of child care providers included directors (5.5\%), teachers and assistant teachers $(33.6 \%)$, specialists and related workers in education services, family services, food services, health services, and special services $(25.4 \%)$, center aide (18.2\%), secretary (8.1\%), bus driver (6.8 \%), custodial $(1.3 \%)$, and others $(1.0 \%)$. The prevalence of overweight/obesity was $73.6 \%$, but only $9.8 \%$ perceived their weight status as obese. The prevalence of discordance between weight status and perception of weight was about $55 \%$. The mean score of nutrition knowledge level among child care providers in MSHS centers was $4.1(\mathrm{SD}=1.4)$ out of 9. Six questions out of nine were answered correctly by $<50 \%$. Question 5 (Are dairy products a good source of calcium?) had the highest percentage of child care providers answering correctly $(96.4 \%)$ whereas question 8 (What percent of your daily calories should come from fat?) had the lowest percentage answering correctly (8.4\%). The food availability related to cost, quality, and access to grocery store was relatively high but about $28 \%$ reported low or very low food security status in this population.

\section{Three patterns of nutritional health attitudes and behaviors}

Table 2 shows the factor loading matrix for three patterns of nutritional health attitudes and behaviors identified by factor analysis among Michigan MSHS child care providers. Three patterns accounted for about $57 \%$ of the total variance in the dataset. The first pattern was negatively associated with body weight satisfaction but positively associated with behaviors related to weight loss attempt and was named the "weight loss practices with weight dissatisfaction". In other words, subjects who had a high score of pattern 1 were more likely to be less satisfied with their body weight and try to lose body weight compared to those who had a low score of the same pattern. The second pattern was characterized by high factor loadings for satisfaction of health and weight status and healthy dietary behaviors, so it was named the "healthy eating behaviors". The first and second patterns accounted for $21.6 \%$ and $21.4 \%$ of the total variance, respectively. The third pattern was positively associated with the awareness that nutrition is importance for health outcomes for themselves as well as MSHS children and accounted for $13.8 \%$ of the total variance. This pattern was named the "better knowledge of nutrition and health".

\section{Associations of sociodemographic and weight-related characteristics with three patterns}

Individuals in the highest tertile of "weight loss practices with weight dissatisfaction" pattern scores were more likely to be older, be obese, and perceive their weight status incorrectly than those in the lowest tertile. The "healthy eating behaviors" pattern scores were not significantly associated with any sociodemographic characteristics. Individuals in the highest tertile of "healthy eating behaviors" pattern scores were more likely to be normal weight and perceive their weight status correctly than those in the lowest tertile. The percentages of White/Caucasian and individuals with high education level ( $\geq$ associate's degree/ certificate or college) were significantly higher in the highest tertile of "better knowledge of nutrition and health" pattern scores than those in the lowest tertile. The "better knowledge of nutrition and health" pattern scores were not associated with weight status and perception of weight (Table 3). 
Table 1 Characteristics of child care providers in Michigan Migrant and Seasonal Head Start centers $(n=307)$

\begin{tabular}{|c|c|}
\hline Characteristics & $\begin{array}{l}\% \text { or } \\
\text { Mean(SD) }\end{array}$ \\
\hline \multicolumn{2}{|l|}{ Gender } \\
\hline Male & 7.8 \\
\hline Female & 92.2 \\
\hline \multicolumn{2}{|l|}{ Age } \\
\hline$<30 y$ & 34.5 \\
\hline $30-49 y$ & 43.0 \\
\hline$\geq 50 y$ & 22.5 \\
\hline \multicolumn{2}{|l|}{ Race/Ethnicity } \\
\hline White/Caucasian & 44.3 \\
\hline Black/African American & 1.6 \\
\hline Hispanic/Latino & 52.5 \\
\hline Other & 1.6 \\
\hline \multicolumn{2}{|l|}{ Marital status } \\
\hline Single & 30.9 \\
\hline Married & 51.1 \\
\hline Cohabitating & 6.8 \\
\hline Separated/Divorced/Widowed & 11.1 \\
\hline \multicolumn{2}{|l|}{ Education level } \\
\hline$\leq$ High school & 54.4 \\
\hline$\geq$ Associate's degree/certificate or college & 45.6 \\
\hline \multicolumn{2}{|l|}{ Weight status } \\
\hline Normal weight & 26.4 \\
\hline Overweight & 24.1 \\
\hline Obese & 49.5 \\
\hline
\end{tabular}

Perception of weight

Underweight

Normal weight

Overweight

Obese

Accordance between weight status and perception of weight

Accordance

Discordance

Nutrition knowledge level (\% of child care providers who answered correctly)

Do drinks, like Fruitopia or Sunny Delight, count as a fruit serving?

Do only fresh fruits and vegetables count towards the recommended daily servings of fruit and vegetables?

Is it okay for children to eat without worrying about fat because they need lots of extra calories to grow?

Are soft drinks low in fat?

Are dairy products a good source of calcium?

Should vitamin and mineral supplements be taken in addition to a healthy diet?
Table 1 Characteristics of child care providers in Michigan Migrant and Seasonal Head Start centers $(n=307)$ (Continued)

How many servings of fruits and vegetables should you 29.5

eat per day?

What percent of your daily calories should come from fat? 8.4

What has the most calories? 38.5

Mean(SD) number of corrected answers

Food availability

I do not buy many fruits and vegetables because they cost too much.

Agree

Neutral

Disagree

I do not buy many fruits and vegetables because my family does not like them.

$\begin{array}{ll}\text { Agree } & 3.3 \\ \text { Neutral } & 6.5 \\ \text { Disagree } & 90.2\end{array}$

The fresh produce in my area is usually high quality.

Agree $\quad 64.2$

Neutral 27.7

Disagree $\quad 8.1$

It is easy to buy food in my area.

$\begin{array}{ll}\text { Agree } & 78.2 \\ \text { Neutral } & 14.7 \\ \text { Disagree } & 7.2\end{array}$

In minutes, how long does it take you to get to the grocery store?

10 or less $\quad 48.5$

$20 \quad 24.4$

$30-16.3$

45 or more $\quad 10.8$

How many times do you visit the grocery store in a month?

$0-1$

$2-4 \quad 49.8$

5 or more $\quad 46.9$

Food security status

High $\quad 52.4$

Marginal 19.9

Low $\quad 16.0$

$\begin{array}{ll}\text { Very low } & 11.7\end{array}$

Associations of nutrition knowledge, food availability, and food security with three patterns

The scores of "weight loss practices with weight dissatisfaction" pattern were not associated with nutrition knowledge, food availability, and food security. For only one question related to food availability ("I do not buy many fruits and vegetables because they cost too much."), the 
Table 2 Factor loading matrix of nutritional health attitudes and behaviors patterns ${ }^{a}$

\begin{tabular}{|c|c|c|c|}
\hline Nutritional health attitudes and behaviors & $\begin{array}{l}\text { Pattern } 1 \text { "Weight loss practices } \\
\text { with weight dissatisfaction" }\end{array}$ & $\begin{array}{l}\text { Pattern } 2 \text { "Healthy } \\
\text { eating behaviors" }\end{array}$ & $\begin{array}{l}\text { Pattern } 3 \text { "Better knowledge } \\
\text { of nutrition and health" }\end{array}$ \\
\hline 1. I am in good health. & & 0.51 & \\
\hline 2. I am satisfied with my weight. & -0.78 & & \\
\hline $\begin{array}{l}\text { 3. Compared to other adults who are my height, I feel my } \\
\text { weight is just right. }\end{array}$ & -0.71 & 0.45 & \\
\hline 4. I have tried to lose or gain weight in the past 12 months. & 0.78 & & \\
\hline 5. I am trying to lose weight now. & 0.86 & & \\
\hline $\begin{array}{l}\text { 6. I am on a special kind of diet, either to lose weight or for } \\
\text { health-related concerns. }\end{array}$ & 0.60 & & \\
\hline 7. My eating habits are healthy. & & 0.81 & \\
\hline 8. I usually limit the amount of high-fat foods I consume. & & 0.78 & \\
\hline 9. I usually limit the amount of high-sugar items I consume. & & 0.72 & \\
\hline 10. I usually eat fruits and vegetables daily. & & 0.57 & \\
\hline 11. I am satisfied with the amount of physical activity I get. & & 0.50 & \\
\hline 12. What I eat affects my chances of developing disease. & & & 0.72 \\
\hline $\begin{array}{l}\text { 13. People who are overweight have a higher risk of health } \\
\text { problems. }\end{array}$ & & & 0.76 \\
\hline 14. Skipping meals affects my ability to do well in the day. & & & 0.69 \\
\hline $\begin{array}{l}\text { 15. I can influence the eating behaviors of migrant head start } \\
\text { children. }\end{array}$ & & & 0.61 \\
\hline Variance explained by each factor & 21.6 & 21.4 & 13.8 \\
\hline
\end{tabular}

${ }^{2}$ The patterns were identified by factor analysis with 15 questions related nutritional health attitudes and behaviors. Factor loadings $<|0.40|$ are not shown for simplicity

percentage of individuals who agreed with this question significantly increased across the tertiles of pattern scores. The scores of "healthy eating behaviors" pattern were associated with high food availability but were not related to nutrition knowledge level and food security status. Individuals who had higher scores of "better knowledge of nutrition and health" pattern showed a significantly higher nutrition knowledge level compared to those who had lower scores (T3 vs. T1: 4.4 vs. 3.7 for mean number of corrected answer for nutrition knowledge questions). However, the scores of "better knowledge of nutrition and health" pattern did not show any associations with the questions for food availability and food security status (Table 4).

\section{Associations of overweight/obesity with three patterns} The multivariate adjusted ORs and $95 \%$ CIs for overweight/obesity across the tertiles of three pattern scores are presented in Fig. 1. After adjusting for potential confounding variables, the scores of "weight loss practices with weight dissatisfaction" pattern were positively associated with the prevalence of overweight/obesity (T2 vs. T1: OR $=5.81,95 \% \mathrm{CI}=2.81-12.05$; T3 vs. T1: OR $=14.89,95 \%$ $\mathrm{CI}=6.18-35.92, p$-value $<0.001)$. The OR for overweight/ obesity in individuals with the highest scores of healthy eating behaviors (pattern 2) was 0.37 (95 \% CI = 0.19$0.75, p$-value $=0.005)$ compared with those with the lowest scores as the reference group. However, one's better knowledge of nutrition and health (pattern 3) was not associated with overweight/obesity.

\section{Discussion}

Michigan MSHS child care providers in this study showed a high prevalence of overweight/obesity (overweight/obesity: $74 \%$, overweight: $24 \%$ and obesity: $50 \%$, respectively), which was higher than the general population of US adults aged 20 years and over (overweight/obesity: $69 \%$, overweight: $34 \%$ and obesity: $35 \%$ in 2009-2012, respectively) [21] and lower than regular Head Start teachers in Texas ( $n=181$ ) (overweight/obesity: $79 \%$, overweight: $24 \%$ and obesity: $55 \%$ in 2008-2009, respectively) [8]. We found three patterns of nutritional health attitudes and behaviors among child care providers in Michigan MSHS centers. These patterns were influenced by sociodemographic characteristics, perception of weight status, nutrition knowledge, and food environments and associated with the prevalence of overweight/obesity.

This high risk of overweight/obesity among child care providers can be explained by their unhealthy attitudes and behaviors. Our data showed that individuals who tried to lose weight with dissatisfaction of weight had a high risk of overweight/obesity but individuals with high satisfaction of health and weight and healthy dietary behaviors showed a low risk of overweight/obesity. Teachers in Texas regular 
Table 3 Sociodemographic and weight-related characteristics across the tertiles of scores of nutritional health attitudes and behaviors patterns

\begin{tabular}{|c|c|c|c|c|c|c|c|c|c|c|c|c|}
\hline & \multicolumn{4}{|l|}{ Pattern 1} & \multicolumn{4}{|l|}{ Pattern 2} & \multicolumn{4}{|l|}{ Pattern 3} \\
\hline & \multicolumn{4}{|c|}{$\begin{array}{l}\text { "Weight loss practices with weight } \\
\text { dissatisfaction" }\end{array}$} & \multicolumn{4}{|c|}{ "Healthy eating behaviors" } & \multicolumn{4}{|c|}{$\begin{array}{l}\text { "Better knowledge of nutrition and } \\
\text { health" }\end{array}$} \\
\hline & $\begin{array}{l}\text { Tertile1 } \\
(n=102)\end{array}$ & $\begin{array}{l}\text { Tertile2 } \\
(n=103)\end{array}$ & $\begin{array}{l}\text { Tertile3 } \\
(n=102)\end{array}$ & $p$-value ${ }^{*}$ & $\begin{array}{l}\text { Tertile1 } \\
(n=102)\end{array}$ & $\begin{array}{l}\text { Tertile2 } \\
(n=103)\end{array}$ & $\begin{array}{l}\text { Tertile3 } \\
(n=102)\end{array}$ & $p$-value* & $\begin{array}{l}\text { Tertile1 } \\
(n=102)\end{array}$ & $\begin{array}{l}\text { Tertile2 } \\
(n=103)\end{array}$ & $\begin{array}{l}\text { Tertile3 } \\
(n=102)\end{array}$ & $p$-value* \\
\hline \multicolumn{13}{|l|}{ Gender (\%) } \\
\hline Male & 13.7 & 2.9 & 6.9 & 0.068 & 7.8 & 6.8 & 8.8 & 0.795 & 9.8 & 6.8 & 6.9 & 0.435 \\
\hline Female & 86.3 & 97.1 & 93.1 & & 92.2 & 93.2 & 91.2 & & 90.2 & 93.2 & 93.1 & \\
\hline \multicolumn{13}{|l|}{ Age (\%) } \\
\hline$<30 y$ & 49.0 & 29.1 & 25.5 & 0.003 & 39.2 & 34.0 & 30.4 & 0.061 & 43.1 & 25.2 & 35.3 & 0.260 \\
\hline $30-49 y$ & 32.4 & 48.5 & 48.0 & & 40.2 & 50.5 & 38.2 & & 37.3 & 50.5 & 41.2 & \\
\hline$\geq 50 y$ & 18.6 & 22.3 & 26.5 & & 20.6 & 15.5 & 31.4 & & 19.6 & 24.3 & 23.5 & \\
\hline \multicolumn{13}{|l|}{ Race/Ethnicity (\%) } \\
\hline White/Caucasian & 44.1 & 40.8 & 48.0 & 0.406 & 41.2 & 42.7 & 49.0 & 0.239 & 33.3 & 46.6 & 52.9 & 0.010 \\
\hline Black/African American & 1.0 & 2.9 & 1.0 & & 2.0 & 1.0 & 2.0 & & 1.0 & 3.9 & 0.0 & \\
\hline Hispanic/Latino & 51.0 & 55.3 & 51.0 & & 55.9 & 52.4 & 49.0 & & 64.7 & 48.5 & 44.1 & \\
\hline Other & 3.9 & 1.0 & 0.0 & & 1.0 & 3.9 & 0.0 & & 1.0 & 1.0 & 2.9 & \\
\hline \multicolumn{13}{|l|}{ Marital status (\%) } \\
\hline Single & 39.2 & 33.0 & 20.6 & 0.066 & 35.3 & 28.2 & 29.4 & 0.230 & 39.2 & 23.3 & 30.4 & 0.290 \\
\hline Married & 43.1 & 54.4 & 55.9 & & 46.1 & 54.4 & 52.9 & & 44.1 & 55.3 & 53.9 & \\
\hline Cohabitating & 9.8 & 3.9 & 6.9 & & 5.9 & 6.8 & 7.8 & & 7.8 & 6.8 & 5.9 & \\
\hline $\begin{array}{l}\text { Separated/Divorced/ } \\
\text { Widowed }\end{array}$ & 7.8 & 8.7 & 16.7 & & 12.8 & 10.7 & 9.8 & & 8.8 & 14.6 & 9.8 & \\
\hline \multicolumn{13}{|l|}{ Education level (\%) } \\
\hline$\leq$ High school & 52.9 & 58.3 & 52.0 & 0.888 & 57.8 & 55.3 & 50.0 & 0.262 & 67.7 & 52.4 & 43.1 & 0.001 \\
\hline $\begin{array}{l}\geq \text { Associate's degree/ } \\
\text { certificate or college }\end{array}$ & 47.1 & 41.8 & 48.0 & & 42.2 & 44.7 & 50.0 & & 32.4 & 47.6 & 56.9 & \\
\hline \multicolumn{13}{|l|}{ Weight status (\%) } \\
\hline Normal weight & 52.9 & 17.5 & 8.8 & $<0.001$ & 18.6 & 24.3 & 36.3 & $<0.001$ & 21.6 & 23.3 & 34.3 & 0.279 \\
\hline Overweight & 27.5 & 26.2 & 18.6 & & 19.6 & 23.3 & 29.4 & & 29.4 & 26.2 & 16.7 & \\
\hline Obese & 19.6 & 56.3 & 72.6 & & 61.8 & 52.4 & 34.3 & & 49.0 & 50.5 & 49.0 & \\
\hline \multicolumn{13}{|l|}{ Perception of weight (\%) } \\
\hline Underweight & 0.0 & 1.9 & 0.0 & $<0.001$ & 2.0 & 0.0 & 0.0 & 0.002 & 2.0 & 0.0 & 0.0 & 0.309 \\
\hline Normal weight & 69.6 & 15.5 & 7.8 & & 18.6 & 33.0 & 41.2 & & 33.3 & 24.3 & 35.3 & \\
\hline Overweight & 29.4 & 77.7 & 68.6 & & 64.7 & 58.3 & 52.9 & & 60.8 & 61.2 & 53.9 & \\
\hline Obese & 1.0 & 4.9 & 23.5 & & 14.7 & 8.7 & 5.9 & & 3.9 & 14.6 & 10.8 & \\
\hline \multicolumn{13}{|c|}{ Accordance between weight status and perception of weight (\%) } \\
\hline Accordance & 63.7 & 29.1 & 43.1 & 0.003 & 41.2 & 39.8 & 54.9 & 0.049 & 40.2 & 48.5 & 47.1 & 0.326 \\
\hline Discordance & 36.3 & 70.9 & 56.9 & & 58.8 & 60.2 & 45.1 & & 59.8 & 51.5 & 52.9 & \\
\hline
\end{tabular}

${ }^{*} p$-value was obtained from the chi-square test for categorical variables

Head Start centers who were at a high prevalence of overweight/obesity had relatively low consumption of fruits and vegetables and high consumption of fried foods while they had dissatisfaction with their weight [8]. Teachers in German kindergarten reported several unhealthy behaviors, such as high screen time and low physical activity level and these behaviors were associated with a high risk of overweight/obesity [22]. However, specific information on nutritional health attitudes and behaviors and their association with weight status among MSHS child care providers is very limited despite their unique characteristics regarding sociodemographics, working hours and 
Table 4 Nutrition knowledge, food availability, and food security across the tertiles of scores of nutritional health attitudes and behaviors patterns

\begin{tabular}{|c|c|c|c|c|c|c|c|c|c|c|c|c|}
\hline & & \multicolumn{4}{|l|}{ Pattern 2} & \\
\hline & \multicolumn{4}{|c|}{$\begin{array}{l}\text { "Weight loss practices with weight } \\
\text { dissatisfaction" }\end{array}$} & \multicolumn{4}{|c|}{ "Healthy eating behaviors" } & \multicolumn{4}{|c|}{$\begin{array}{l}\text { "Better knowledge of nutrition and } \\
\text { health" }\end{array}$} \\
\hline & $\begin{array}{l}\text { Tertile1 } \\
(n=102)\end{array}$ & $\begin{array}{l}\text { Tertile } 2 \\
(n=103)\end{array}$ & $\begin{array}{l}\text { Tertile } 3 \\
(n=102)\end{array}$ & $\overline{p \text {-value }}{ }^{*}$ & $\begin{array}{l}\text { Tertile1 } \\
(n=102)\end{array}$ & $\begin{array}{l}\text { Tertile } 2 \\
(n=103)\end{array}$ & $\begin{array}{l}\text { Tertile } 3 \\
(n=102)\end{array}$ & $p$-value ${ }^{*}$ & $\begin{array}{l}\text { Tertile1 } \\
(n=102)\end{array}$ & $\begin{array}{l}\text { Tertile } 2 \\
(n=103)\end{array}$ & $\begin{array}{l}\text { Tertile } 3 \\
(n=102)\end{array}$ & $p$-value* \\
\hline \multicolumn{13}{|c|}{ Nutrition knowledge level (\%) } \\
\hline $1-2$ & 9.8 & 7.8 & 10.8 & 0.843 & 9.8 & 11.7 & 6.9 & 0.489 & 16.7 & 6.8 & 4.9 & 0.002 \\
\hline $3-4$ & 52.0 & 60.2 & 52.9 & & 53.9 & 55.3 & 55.9 & & 57.8 & 52.4 & 54.9 & \\
\hline $5-6$ & 34.3 & 26.2 & 31.4 & & 33.3 & 27.2 & 31.4 & & 22.6 & 36.9 & 32.4 & \\
\hline $7-9$ & 3.9 & 5.8 & 4.9 & & 2.9 & 5.8 & 5.9 & & 2.9 & 3.9 & 7.8 & \\
\hline $\begin{array}{l}\text { Mean(SD) number } \\
\text { of corrected answers }\end{array}$ & $4.1(1.4)$ & $4.1(1.4)$ & $4.1(1.4)$ & 0.955 & $4.1(1.4)$ & $4.0(1.4)$ & $4.2(1.3)$ & 0.534 & $3.7(1.3)$ & $4.2(1.3)$ & $4.4(1.4)$ & 0.002 \\
\hline \multicolumn{13}{|l|}{ Food availability (\%) } \\
\hline \multicolumn{13}{|c|}{ I do not buy many fruits and vegetables because they cost too much. } \\
\hline Agree & 15.7 & 27.2 & 30.4 & 0.002 & 34.3 & 20.4 & 18.6 & $<0.001$ & 27.5 & 25.2 & 20.6 & 0.457 \\
\hline Neutral & 12.8 & 16.5 & 19.6 & & 22.6 & 16.5 & 9.8 & & 11.8 & 20.4 & 16.7 & \\
\hline Disagree & 71.6 & 56.3 & 50.0 & & 43.1 & 63.1 & 71.6 & & 60.8 & 54.4 & 62.8 & \\
\hline \multicolumn{13}{|c|}{ I do not buy many fruits and vegetables because my family does not like them. } \\
\hline Agree & 4.9 & 2.9 & 2.0 & 0.620 & 5.9 & 3.9 & 0.0 & 0.013 & 2.9 & 3.9 & 2.9 & 0.620 \\
\hline Neutral & 4.9 & 6.8 & 7.8 & & 8.8 & 4.9 & 5.9 & & 6.9 & 8.7 & 3.9 & \\
\hline Disagree & 90.2 & 90.3 & 90.2 & & 85.3 & 91.3 & 94.1 & & 90.2 & 87.4 & 93.1 & \\
\hline \multicolumn{13}{|c|}{ The fresh produce in my area is usually high quality. } \\
\hline Agree & 60.8 & 60.2 & 71.6 & 0.229 & 53.9 & 55.3 & 83.3 & $<0.001$ & 52.9 & 74.8 & 64.7 & 0.156 \\
\hline Neutral & 31.4 & 31.1 & 20.6 & & 34.3 & 35.0 & 13.7 & & 37.3 & 19.4 & 26.5 & \\
\hline Disagree & 7.8 & 8.7 & 7.8 & & 11.8 & 9.7 & 2.9 & & 9.8 & 5.8 & 8.8 & \\
\hline \multicolumn{13}{|c|}{ It is easy to buy food in my area. } \\
\hline Agree & 81.4 & 76.7 & 76.5 & 0.237 & 72.6 & 72.8 & 89.2 & 0.009 & 71.6 & 81.6 & 81.4 & 0.408 \\
\hline Neutral & 13.7 & 16.5 & 13.7 & & 18.6 & 18.5 & 6.9 & & 22.6 & 11.7 & 9.8 & \\
\hline Disagree & 4.9 & 6.8 & 9.8 & & 8.8 & 8.7 & 3.9 & & 5.9 & 6.8 & 8.8 & \\
\hline \multicolumn{13}{|c|}{ In minutes, how long does it take you to get to the grocery store? } \\
\hline 10 or less & 48.0 & 50.5 & 47.1 & 0.831 & 47.1 & 42.7 & 55.9 & 0.855 & 53.9 & 48.5 & 43.1 & 0.626 \\
\hline 20 & 26.5 & 23.3 & 23.5 & & 27.5 & 27.2 & 18.6 & & 19.6 & 23.3 & 30.4 & \\
\hline 30 & 13.7 & 16.5 & 18.6 & & 17.7 & 17.5 & 13.7 & & 14.7 & 17.5 & 16.7 & \\
\hline 45 or more & 11.8 & 9.7 & 10.8 & & 7.8 & 12.6 & 11.8 & & 11.8 & 10.7 & 9.8 & \\
\hline \multicolumn{13}{|c|}{ How many times do you visit the grocery store in a month? } \\
\hline $0-1$ & 3.9 & 2.9 & 2.9 & 0.531 & 2.0 & 3.9 & 3.9 & 0.616 & 2.9 & 4.9 & 2.0 & 0.766 \\
\hline $2-4$ & 52.9 & 46.6 & 50.0 & & 47.1 & 55.3 & 47.1 & & 48.0 & 51.5 & 50.0 & \\
\hline 5 or more & 43.1 & 50.5 & 47.1 & & 51.0 & 40.8 & 49.0 & & 49.0 & 43.7 & 48.0 & \\
\hline \multicolumn{13}{|l|}{ Food security status (\%) } \\
\hline High & 62.8 & 46.6 & 48.0 & 0.088 & 50.0 & 48.5 & 58.8 & 0.101 & 48.0 & 45.6 & 63.7 & 0.077 \\
\hline Marginal & 17.7 & 16.5 & 25.5 & & 20.6 & 19.4 & 19.6 & & 22.6 & 24.3 & 12.8 & \\
\hline Low & 8.8 & 27.2 & 11.8 & & 15.7 & 16.5 & 15.7 & & 16.7 & 15.5 & 15.7 & \\
\hline Very low & 10.8 & 9.7 & 14.7 & & 13.7 & 15.5 & 5.9 & & 12.8 & 14.6 & 7.8 & \\
\hline
\end{tabular}




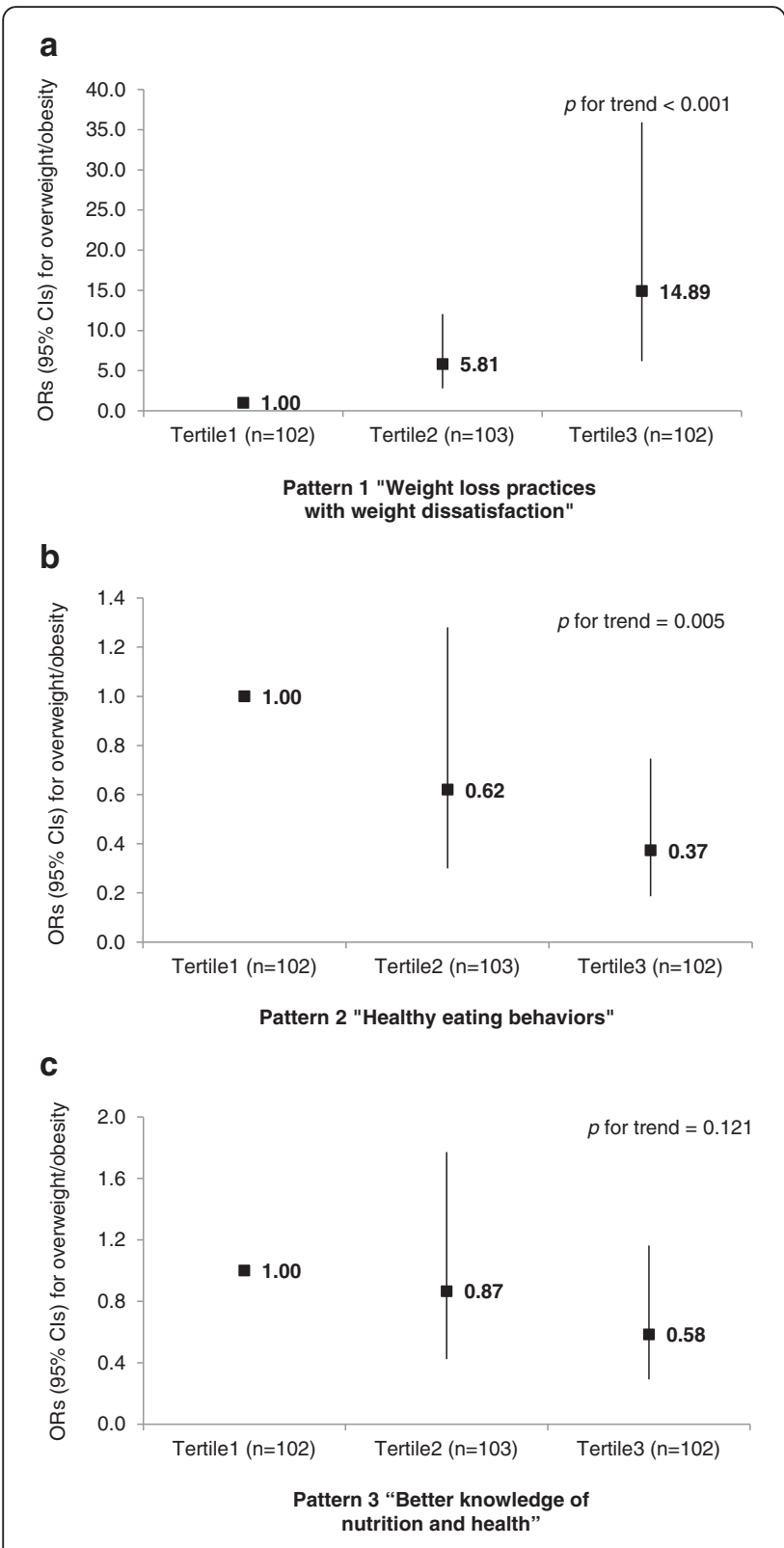

Fig. 1 Multivariate odds ratios (ORs) and $95 \%$ confidence intervals (Cls) for overweight/obesity across the tertiles of scores of nutritional health attitudes and behaviors patterns'. 'Multivariate logistic regression was performed to estimate the $\mathrm{ORs}, 95 \% \mathrm{Cls}$, and $p$ values for the prevalence of overweight/obesity across tertiles of pattern scores, taking the lowest tertile group as the reference group after adjustment for gender (male or female), age ( $<30 y, 30-49 y$, or $\geq 50 y)$, race/ethnicity (White/Caucasian, Black/African American, Hispanic/Latino, or other), marital status (single, married, cohabitating, or separated/divorced/ widowed), and education level ( $\leq$ high school or $\geq$ associate's degree/ certificate or college)

environments, children they serve, and knowledge about nutrition and health, which might be different from those of regular Head Start or kindergarten teachers.
In this study, nutritional health attitudes and behaviors of child care providers were influenced by their nutrition knowledge, perception of weight, food availability, and food security status. Nutrition knowledge among child care providers is limited and their personal dietary behaviors and food practices in classroom reflect this low level of nutrition knowledge $[7,8]$. The insufficient nutrition knowledge and inaccurate perception of weight of child care providers may result in unfavorable health outcomes of themselves and children they serve. Lack of nutrition knowledge and cultural beliefs of Head Start staff were founded as important barriers to children's healthy eating based on the 2008 cross-sectional study [23].

Our results, along with those of other studies, suggest that greater emphasis on developing and incorporating nutrition education or intervention targeting MSHS child care providers to ensure their health and wellbeing, as well as their ability to deliver MSHS programs to young children. Child care providers might have the important potential to influence nutritional health risks of children either directly or indirectly through transferring inappropriate attitudes and behaviors to children and providing misinformation and inappropriate advice and education [4]. Feeding behaviors of Head Start child care providers directly influenced on children's food consumption [6]. However, there have been few studies that confirmed this important findings and interventions to promote nutrition knowledge and healthy dietary behaviors for child care providers at child care facilities [7, 8, 24]. Many efforts to reduce childhood overweight/obesity in Head Start programs have focused on family child care providers and their feeding methods $[23,25,26]$. According to a national survey of 1,583 Head Start centers in 2008, about 60 \% held workshops to train new staff about feeding children and only $50 \%$ offered workshops or activities for employees to improve their own eating behaviors [25].

In the current study, child care providers' nutritional health attitudes and behaviors were determined by their socioeconomic status, perception of weight, nutrition knowledge, and food environments and needed to be changed to reduce the risk of overweight/obesity. According to our findings, the social cognitive theory-based intervention on dietary behaviors and nutrition knowledge can be suggested to expand knowledge on nutrition, health, and weight perception and improve eating behaviors of MSHS child care providers. This theory incorporates the interdependent relationships between personal, behavioral, and environmental factors to explain healthy eating behaviors [27]. The theory has widely been used for nutrition and/or health related interventions [28-31]. This approach might be an effective way to help MSHS child care providers to have healthy body image and appropriate weight control practices, support healthy dietary behaviors, and build nutrition knowledge and awareness of the importance of 
nutrition and health. Considering the fact that high proportion of Latino/Hispanic ethnicity among MSHS child care providers, culturally relevant and specific tailored interventions are also needed.

Findings of our study offer many opportunities and directions for future studies for this hard-to-reach and high risk group in the US although there are several limitations. The present study was based on a local-specific smallscaled and one year needs assessment investigation. Thus, our findings need to be confirmed through large-scaled studies at state-wide or national levels. This study relied on self-administered data from MSHS child care providers, which may influence the extent to which child care providers accurately report their nutritional health attitudes and behaviors and weight status although we trained directors of each center to guide their child care providers about the procedures of the survey. The survey questionnaire used in this study was not validated in MSHS child care providers, but each part of survey questionnaire was adopted from the validated questionnaires in low-income, minority populations at the fourth-grade reading level. To our knowledge, this study is the first attempt to examine nutritional health attitudes and behaviors and their associations with overweight/obesity among child care providers in MSHS centers, who are responsible for educating children and parents from MSFW families at a high risk for nutritional health problems.

\section{Conclusions}

In conclusion, child care providers working in Michigan MSHS centers had specific nutritional health attitudes and behaviors associated with the prevalence of overweight/ obesity. The current study supports that additional health interventions, including nutrition education targeting MSHS child care providers are urgently necessary. This might be helpful to improve their own health as well as to enhance their role as role models and educators in child care settings. Furthermore, these efforts for child care providers may be an efficient and effective non-invasive approach for reaching and helping large numbers of young children enrolled in MSHS programs. This practice has a great potential to decrease the growing gap in health disparity between the majority population and vulnerable group to nutritional health risk, such as MSFW families. Further studies are needed to focus on evaluating the effects of health interventions targeting MSHS child care providers on children's health status.

\footnotetext{
Abbreviations

BMI, body mass index; Cl, confidence interval; MSFW, migrant and seasonal farm worker; MSHS, migrant and seasonal head start; OR, odds ratio; SD, standard deviation.

Funding

This study was partially supported by Michigan Telamon Corporation, MSU Extension, Julian Samora Research Institute, College Assistance Migrant
}

Program Scholars Initiative (CAMP) at MSU, and the National Institutes of Health NIH-NHLBI grant award 5 R25 HL108864 to ETC.

\section{Availability of data and materials}

We do not wish to share our data before we have thoroughly analyzed it. All data sources described in this study are directed at the corresponding author.

\section{Authors' contributions}

WOS formulated the study question and developed study design. VN and AG collected data. SS analyzed data and drafted the manuscript. WOS, SS, and ETC. contributed to the interpretation of the results and revised the manuscript. WOS had primary responsibility for final content. All authors read and approved the final manuscript.

\section{Competing interests}

The authors declare that they have no competing interests.

Consent for publication

Not applicable.

\section{Ethics approval and consent to participate}

The formal approval to conduct this needs assessment was obtained by the Institutional Review Board of the Michigan Telamon Corporation. Informed written consent was obtained from each child care providers and data were released to the research team collaborators for this report.

\section{Author details}

'Department of Food Science and Human Nutrition, Michigan State University, East Lansing, Ml 48824, USA. ${ }^{2}$ Department of Medicine-College of Human Medicine, Michigan State University, East Lansing, MI 48824, USA.

Received: 12 February 2016 Accepted: 20 July 2016

Published online: 27 July 2016

References

1. Schmit S. Migrant and Seasonal Head Start Participants, Programs, Families and Staff in 2013. 2014. http://www.clasp.org/resources-and-publications/ publication-1/MHSH-PIR-2013-Fact-Sheet.pdf. Accessed 06 Jul 2015

2. Larson AC. Migrant and Seasonal Farmworker Enumeration Profiles. 2013. https://www.michigan.gov/documents/dhs/FarmworkerReport_430130_7. pdf. Accessed 15 Oct 2015.

3. Walker C. Head Start Participants, Programs, Families and Staff in 2013. 2014 http://www.clasp.org/resources-and-publications/publication-1/HSpreschoolPIR-2013-Fact-Sheet.pdf. Accessed 07 Aug 2015.

4. Lanigan JD. The relationship between practices and child care providers beliefs related to child feeding and obesity prevention. J Nutr Educ Behav. 2012:44:521-9.

5. Yager Z, O'Dea JA. The role of teachers and other educators in the prevention of eating disorders and child obesity: what are the issues? Eat Disord. 2005;13:261-78.

6. Hughes $\mathrm{SO}$, Patrick $\mathrm{H}$, Power TG, Fisher JO, Anderson CB, Nicklas TA. The impact of child care providers' feeding on children's food consumption. J Dev Behav Pediatr. 2007;28:100-7.

7. Nahikian-Nelms M. Influential factors of caregiver behavior at mealtime: a study of 24 child-care programs. J Am Diet Assoc. 1997;97:505-9.

8. Sharma S, Dortch KS, Byrd-Williams C, Truxillio JB, Rahman GA, Bonsu P, et al. Nutrition-related knowledge, attitudes, and dietary behaviors among head start teachers in Texas: a cross-sectional study. J Acad Nutr Diet. 2013; 113:558-62

9. Kilanowski JF, Ryan-Wenger NA. Health status in an invisible population carnival and migrant worker children. Western J Nurs Res. 2007;29:100-20.

10. Nichols M, Stein AD, Wold JL. Health status of children of migrant farm workers: farm worker family health program, Moultrie, Georgia. Am J Public Health. 2014;104:365-70

11. Song WO, Song S, Gonzalez A, Shin D, Nieves V. Parents' BMI and weight perception are associated with overweight and obesity among children in Michigan migrant and seasonal farm worker families. J J Commun Med. 2015;1:003.

12. Telamon Corporation. Michigan migrant head start locations. http://www. telamon.org/michigan-migrant-head-start.aspx. Accessed 25 Sep 2015. 
13. Ali SM, Lindstrom M. Socioeconomic, psychosocial, behavioural, and psychological determinants of BMl among young women: differing patterns for underweight and overweight/obesity. Eur J Public Health. 2005;16:324-30.

14. Mase T, Miyawaki C, Kouda K, Fujita Y, Ohara K, Nakamura H. Relationship of a desire of thinness and eating behavior among Japanese underweight female students. Eat Weight Disord. 2013;18:125-32.

15. Centers for Disease Control and Prevention. Defining Adult Overweight and Obesity. http://www.cdc.gov/obesity/adult/defining.html. Accessed 28 Sep 2015.

16. Campbell K, Crawford D, Jackson M, Cashel K, Worsley A, Gibbons K, et al. Family food environments of 5-6-year-old-children: does socioeconomic status make a difference? Asia Pac J Clin Nutr. 2002;Suppl 3:S553-61.

17. Economic Research Service. U.S. Household food security survey module: three-stage design, with screeners. 2012. http://www.ers.usda.gov/datafiles/ Food_Security_in_the_United_States/Food_Security_Survey_Modules/ hh2012.pdf. Accessed 11 May 2015.

18. Kubik MY, Lytle LA, Hannan PJ, Story M, Perry CL. Food-related beliefs, eating behavior, and classroom food practices of middle school teachers. J Sch Health. 2002;72:339-45.

19. Rossiter M, Glanville T, Taylor J, Blum I. School food practices of prospective teachers. J Sch Health. 2007;77:694-700.

20. Hu FB. Dietary pattern analysis: a new direction in nutritional epidemiology. Curr Opin Lipidol. 2002;13:3-9.

21. National Center for Health Statistics. Health, United States, 2014: with special feature on adults aged 55-64. 2015. http://www.cdc.gov/nchs/data/hus/ hus14.pdf. Accessed 28 Sep 2015

22. Hoffmann SW, Tug S, Simon P. Obesity prevalence and unfavorable health risk behaviors among German kindergarten teachers: cross-sectional results of the kindergarten teacher health study. Bmc Public Health. 2013;13:927.

23. Hughes CC, Gooze RA, Finkelstein DM, Whitaker RC. Barriers to obesity prevention in Head Start. Health Aff (Millwood). 2010;29:454-62.

24. Anderson LM, Quinn TA, Glanz K, Ramirez G, Kahwati LC, Johnson DB, et al. The effectiveness of worksite nutrition and physical activity interventions for controlling employee overweight and obesity: a systematic review. Am J Prev Med. 2009;37:340-57.

25. Gooze RA, Hughes CC, Finkelstein DM, Whitaker RC. Reaching staff, parents, and community partners to prevent childhood obesity in head start, 2008. Prev Chronic Dis. 2010;7:A54.

26. Whitaker RC, Gooze RA, Hughes CC, Finkelstein DM. A National survey of obesity prevention practices in Head Start. Arch Pediat Adol Med. 2009;163: $1144-50$.

27. Sheeshka JD, Woolcott DM, Mackinnon NJ. Social cognitive theory as a framework to explain intentions to practice healthy eating behaviors J Appl Soc Psychol. 1993;23:1547-73.

28. Baranowski T, Davis M, Resnicow K, Baranowski J, Doyle C, Lin LS, et al. Gimme 5 fruit, juice, and vegetables for fun and health: outcome evaluation. Health Educ Behav. 2000;27:96-111.

29. Dzewaltowski DA, Estabrooks PA, Welk G, Hill J, Milliken G, Karteroliotis K, et al. Healthy youth places: a randomized controlled trial to determine the effectiveness of facilitating adult and youth leaders to promote physical activity and fruit and vegetable consumption in middle schools. Health Educ Behav. 2009;36:583-600

30. Branscum P, Kaye G, Warner J. Impacting dietary behaviors of children from low income communities: an evaluation of a theory-based nutrition education program. Californian J Health Promot. 2013;11:43-52.

31. Powers AR, Struempler BJ, Guarino A, Parmer SM. Effects of a nutrition education program on the dietary behavior and nutrition knowledge of second-grade and third-grade students. J Sch Health. 2005;75:129-33.

\section{Submit your next manuscript to BioMed Central and we will help you at every step:}

- We accept pre-submission inquiries

- Our selector tool helps you to find the most relevant journal

- We provide round the clock customer support

- Convenient online submission

- Thorough peer review

- Inclusion in PubMed and all major indexing services

- Maximum visibility for your research

Submit your manuscript at www.biomedcentral.com/submit

) Biomed Central 